\title{
Tolerancja ultrahipofrakcjonowanej radioterapii metodą SBRT raka stercza przy użyciu aparatu Cyberknife
}

\section{Treatment tolerance of ultrahypofractionated radiotherapy SBRT using Cyberknife platform for prostate cancer}

\author{
Aleksandra Mańczak ${ }^{1}$ Piotr Milecki ${ }^{2,3}$ \\ ${ }^{1}$ Zakład Radioterapii I, Wielkopolskie Centrum Onkologii, Poznań, Polska \\ ${ }^{2}$ Oddział Radioterapii Onkologicznej I i Zakład Radioterapii I, Wielkopolskie Centrum Onkologï, Poznań, Polska \\ ${ }^{3}$ Katedra Elektroradiologii, Uniwersytet Medyczny im. Karola Marcinkowskiego w Poznaniu
}

\section{Streszczenie}

Rak stercza jest najczęściej występującym nowotworem wśród mężczyzn po 60 roku życia. Radioterapia (RT) będąca jednym z najmniej inwazyjnych sposobów leczenia, często jest skojarzona z innymi metodami lub jest stosowana samodzielnie. W leczeniu raka stercza coraz częściej stosowana jest także RT hipofrakcjonowana polegająca na podaniu większej dawki frakcyjnej aniżeli konwencjonalna, zachowując przy tym mniejszą dawkę całkowitą, w porównaniu do napromieniania konwencjonalnego. Hipofrakcjonowana RT stereotaktyczna (SBRT) będąca przedmiotem tego badania, była realizowana na aparacie Cyberknife. Tolerancję leczenia można określić jako stopień występowania powikłań po zastosowanej RT. Jeśli skutki uboczne leczenia występują rzadko, są słabo nasilone i nie powodują obniżenia jakości życia pacjenta tolerancja leczenia jest dobra.

W niniejszej pracy zbadano ocenę tolerancji leczenia hipofrakcjonowaną RT u pacjentów z rakiem stercza, leczonych w Zakładzie Radioterapii I w Wielkopolskim Centrum Onkologii w latach 2013-2014. Chorzy byli napromieniani na aparacie Cyberknife metodą SBRT z dawką frakcyjną 7,o Gy - 7,25 Gy podawaną 5 krotnie, co dwa dni, do dawki całkowitej 35,o Gy - 36,25 Gy. Oceny tolerancji terapii dokonano na podstawie wypełnianych przez pacjentów ankiet składających się z kwestionariusza IPSS wypełnianych w okresie

Adres do korespondencji

Aleksandra Mańczak

Zakład Radioterapii I,

Wielkopolskie Centrum Onkologii, ul. Garbary 15, 61-866 Poznań, Polska

e-mail: manczakola@gmail.com 
przed leczeniem, po podaniu ostatniej frakcji, po 1 oraz 24 miesiącach od zakończonej RT. Średnia wieku pacjentów wynosiła 69 lat, średni wynik PSA - 9, a średni wynik sumy Gleason - 6.

Na podstawie uzyskanych wyników stwierdzono, że u wszystkich pacjentów wystąpiły objawy ze strony układu moczowego w okresie podania ostatniej frakcji napromieniania oraz miesiąca po zakończeniu leczenia, natomiast po 24 miesiącach od RT poziom ten był porównywany z wynikiem przed leczeniem. Wyniki badania potwierdzają dobrą tolerancję hipofrakcjonowanej SBRT raka stercza, co pokrywa się z aktualnym stanem wiedzy na ten temat i sugerują, że SBRT ze względu na krótszy czas leczenia, równie wysoką skuteczność oraz dobrą tolerancję, w przyszłości mogłaby zastąpić konwencjonalne metody RT w leczeniu raka gruczołu krokowego.

\section{Abstract}

Prostate cancer is the most common cancer among men over 60 years of age. Treatment of prostate cancer includes surgery, hormone therapy or radiotherapy. Radiotherapy is the least invasive treatment, often combined with other methods or is used alone. Ultrahypofractionated stereotactic radiotherapy (SBRT), which was the subject of this study, in the Greater Poland Cancer Center was carried out on the Cyberknife System.

Treatment tolerance can be defined as the degree of occurrence of complications after the therapy. If the side effects of treatment are rare, they are weak and do not reduce the patient's quality of life - the tolerance of treatment is good.

This study presented the results of tolerance on ultrahypofractionated radiotherapy treatment in patients with prostate cancer treated at the Radiation Oncology Department I in Greater Poland Cancer Center. The patients were irradiated on the Cyberknife using the SBRT method with a dose of 7.0 Gy -7.25 Gy, administered 5 times every other day, up to a total dose of 35.0 Gy - 36.25Gy. Assessment of tolerance of therapy was established on the basis of patient-filled surveys of the IPSS completed in the pre-treatment period, after the last fraction, 1 and 24 months after the end of the RT. Average age of patients was 69 years, the average PSA score was 9, and the average Gleason score was 6.

Based on our results all patients had a worsening of the urinary tract symptoms during the time of last irradiation fraction and one month after the end of treatment, while at 24 months after RT, this level comparable to the pre-treatment outcome. This phenomenon is associated with the occurrence of the typical radiation reaction for radiotherapy. The results of the study confirm good tolerance of SBRT which coincides with the current state of knowledge and suggest that SBRT due to shorter treatment time, equally high efficacy and good tolerance, could in the future replace conventional radiotherapy schedules in treatment of prostate cancer.

Stowa kluczowe: rak stercza, radioterapia, SBRT, tolerancja leczenia

Key words: prostate cancer, radiotherapy, SBRT, tolerance of radiotherapy

\section{Wprowadzenie}

Rak stercza jest najczęściej występującym nowotworem u mężczyzn w Polsce [1,2]. W przypadku leczenia raka stercza metodą SBRT (ang. Stereotactic Body Radiation) w trakcie jednej sesji terapeutycznej podawana jest dawka około 7 Gy [3,4]. Dzięki temu czas terapii zostaje skrócony do 1 tygodnia, co jest zdecydowanie wygodniejszym i bardziej ekonomicznym rozwiązaniem dla pacjenta. Prowadzone od wielu lat badania nad tą metodą stwierdzają, że nie ma znaczących różnic zarówno w skuteczności leczenia jak i w częstotliwości występowania powikłań leczenia raka stercza z wykorzystaniem ultrahipofrakcjonowania (SBRT) w stosunku do konwencjonalnego frakcjonowania. Leczenie raka stercza metodą SBRT na aparacie Cyberknife polega na podawaniu wysokiej dawki promieniowania rzędu 7,25 Gy w 5 frakcjach, w odstępach dwudniowych. Dawka całkowita jaką otrzymuje się w targecie obejmującym gruczoł krokowy wraz z marginesem wynosi 36,25 Gy [5]. Praca ma na celu zbadanie tolerancji leczenia raka stercza na aparacie Cyberknife w Zakładzie Radioterapii I w Wielkopolskim Centrum Onkologii w Poznaniu. Dobrą tolerancję terapii zdefiniować można 
jako brak ostrych odczynów popromiennych ze strony układu moczowo-płciowego oraz braku wpływu leczenia na obniżenie jakości życia pacjentów na przełomie 2 lat od leczenia radioterapeutycznego [6,7]. Oczekiwane wyniki badania mają stanowić potwierdzenie hipotezy o dobrej tolerancji leczenia raka stercza z zastosowaniem metody SBRT na aparacie Cyberknife [8,9].

\section{Cel pracy}

Głównym celem niniejszej pracy jest ocena tolerancji leczenia pacjentów z rakiem stercza metodą SBRT realizowanej na aparacie Cyberknife. Dla powyższego celu poddano analizie nasilenie dolegliwości spowodowanych leczeniem raka stercza na podstawie kwestionariusza Międzynarodowej Skali Objawów Związanych z Prostatą (ang. International Prostate Symptom Score, IPSS) przed leczeniem, bezpośrednio po ostatniej frakcji oraz 1 i 24 miesiące po radioterapii.

\section{Materiał i metody}

Przedmiotem badania jest ocena tolerancji leczenia chorych z rakiem prostaty, leczonych metodą radioterapii stereotaktycznej na aparacie Cyberknife w Wielkopolskim Centrum Onkologii w okresie od 2013 do 2014 roku.

Chorych w zależności od stanu ogólnego, wieku, wielkości gruczołu krokowego napromieniano co drugi dzień dawką frakcyjną 7,o Gy lub 7,25 Gy do dawki całkowitej wynoszącej 35,o Gy lub 36,25 Gy. Do oceny tolerancji kwestionariusza Międzynarodowej Skali Objawów Związanych z Prostatą (ang. International Prostate Symptom Score, IPSS). Zebrane dane dotyczyły okresu z przed leczenia, bezpośrednio po leczeniu oraz 1 i 24 miesiące po zakończonej RT.

Badanie przeprowadzono na grupie 44 pacjentów. W analizie. Uwzględniono liczbę obserwacji do czterech, które obejmowały okres przed RT, koniec RT, 1 miesiąc oraz 24 miesiące po zakończeniu leczenia. Średnia wieku pacjentów to 69 lat (maximum 83 lata, minimum 57 lata), średni wynik PSA wśród badanych wynosił 9 (maximum 20, minimum 2), a średni wynik sumy Gleason wynosił 6 (maximum 7, minimum 5).

Pacjenci byli napromieniani metodą ultrahipofrakcjonowania dawką frakcyjną 7,0 Gy lub 7,25 Gy podawaną 5 razy, co dwa dni do dawki całkowitej wynoszącej 35,o Gy lub 36,25 Gy.

Dane $\mathrm{z}$ wypełnianych przez pacjentów ankiet zbierane były odnośnie zgłaszanych przez chorych dolegliwości związanych z rakiem stercza oraz leczeniem.

Do oceny stopnia nasilenia objawów ze strony prostaty użyto Kwestionariusza Międzynarodowej Skali Punktowej Objawów Towarzyszących Chorobom Prostaty (International Prostate Symptom Score, IPSS).

Ankieta w powyższym kwestionariuszu zawiera osiem pytań, w tym:

- pytania 1-7 - dotyczą objawów ze strony układu moczowego,

- pytanie 8 - oceny jakości życia pacjenta.

Wypełniający ankietę ocenia stopnień dolegliwości wg. sześciostopniowej skali punktowej, gdzie o to najmniejsza wartość i oznacza, że pacjent nigdy nie miał podobnych dolegliwości, natomiast 5 to liczba największa, oznaczająca bardzo częste występowanie symptomów. W ostatnim pytaniu o ocenę jakości życia, największą wartością jest liczba 6 oznaczająca bardzo złe samopoczucie pacjenta.

Punkty z każdego pytania należy zsumować i otrzymany wynik zinterpretować wg następujących wartości:

- o-7 lekkie nasilenie objawów,

- 8-19 średnie nasilenie objawów,

- 20-41 poważne nasilenie objawów.

\section{- Analiza statystyczna}

Do analizy statystycznej przeprowadzonego badania użyto programu Statistica oraz PQStat. Do porównania wyników użyto testu Friedmana oraz testu korelacji Spearmana. Za pomocą testu Friedmana porównano wyniki zawarte w poszczególnych kwestionariuszach w różnych okresach leczenia - przed RT, po RT, 1 miesiąc po RT oraz 24 miesiące po RT. Powyższe przeprowadzono w celu analizy zmiany stopnia nasilenia objawów według kwestionariusza IPSS w trakcie całego okresu obserwacji pacjentów. 


\section{Wyniki}

Do oceny stopnia nasilenia objawów ze strony układu moczowo- płciowego użyto kwestionariusza IPSS. Badani wypełniali ankietę przed leczeniem, po ostatniej frakcji, po 1 miesiącu od zakończenia leczenia oraz po 24 miesiącach.

Pytań w ankiecie było osiem, w tym siedem dotyczyło zaburzeń w oddawaniu moczu, a jedno pytanie dotyczyło jakości życia pacjenta.

Maksymalny wynik jaki można było otrzymać wynosił 41 punktów. Wynik od o do 7 wskazywał na lekkie nasilenie objawów, wartości od 8 do 19 to średnie nasilenie, a wynik od 20 do 41 świadczył o silnym stopniu dolegliwości. Wyniki porównania stopnia nasilenia symptomów przed leczeniem do wyników po leczeniu radioterapeutycznym według kwestionariusza IPSS.

Według skali IPSS przed leczeniem u 20\% występowało poważne nasilenie, u 48\% na średnie i u 32\% lekkie nasilenie objawów związanych z funkcjonowaniem układu moczowego. Bezpośrednio po podaniu 5 frakcji napromieniania nastąpił wzrost nasilenia objawów i wynosił odpowiednio: $52 \%$ poważne nasilenie objawów, 32\% średnie, $16 \%$ lekkie nasilenie.

Po upływie 24 miesięcy od zakończenia radioterapii nastąpiło znaczne obniżenie wartości udziału pacjentów z poważnym nasileniem objawów - wynik ten wynosił tylko 16\%. Jest to mniejsza wartość niż przed rozpoczęciem radioterapii, co może świadczyć o dobrej tolerancji leczenia oraz braku występowania późnych odczynów popromiennych.

Tabela 1. Stopień nasilenia objawów ze strony układu moczowo- płciowego w zależności od okresu RT.

\begin{tabular}{|c|c|c|c|c|}
\hline $\begin{array}{c}\text { Stopień nasilenia } \\
\text { objawów }\end{array}$ & IPSS przed RT & IPSS koniec RT & IPSS 1 mies. & IPSS 24 mies. \\
\hline Lekki & $32 \%$ & $16 \%$ & $9 \%$ & $27 \%$ \\
\hline Średni & $48 \%$ & $32 \%$ & $45 \%$ & $57 \%$ \\
\hline Poważny & $20 \%$ & $52 \%$ & $45 \%$ & $16 \%$ \\
\hline
\end{tabular}

Średni wynik sumy IPSS dla okresu przez radioterapią wynosił 12,11 natomiast na końcu RT wynik ten gwałtownie wzrósł do 18,6. Spowodowane było to prawdopodobnie wczesnymi odczynami popromiennymi oraz występującymi dolegliwościami takimi jak zaburzenia oddawania moczu. Objawy te już po miesiącu od zakończenia leczenia zaczęły ustępować (wynik średniej 17,73), a po 24 miesiącach poziom nasilenia dolegliwości był zbliżony do poziomu zanotowanego przed rozpoczęciem leczenia (tabela nr 1-2).

Tabela 2. Statystyka opisowa w poszczególnych fazach leczenia i obserwacji: IPSS.

\begin{tabular}{|c|c|c|c|c|c|c|c|c|}
\hline Zmienna & $\mathrm{N}$ & Średnia & Mediana & Min. & Max. & Q1 & Q3 & $\Sigma$ \\
\hline IPSS przed RT & 44 & 12,11 & 10,00 & 0,00 & 30,00 & 5,00 & 17,00 & 8,14 \\
\hline IPSS koniec RT & 44 & 18,60 & 20,50 & 0,00 & 37,00 & 11,00 & 25,50 & 9,51 \\
\hline IPSS 1 mies. & 44 & 17,73 & 18,00 & 0,00 & 33,00 & 10,50 & 25,50 & 8,64 \\
\hline IPSS 24 mies. & 44 & 12,55 & 12,00 & 0,00 & 29,00 & 7,00 & 17,50 & 7,28 \\
\hline
\end{tabular}

Legenda: $\sigma$ - odchylenie standardowe, Q1- kwartyl dolny, Q3 - kwartyl górny. 


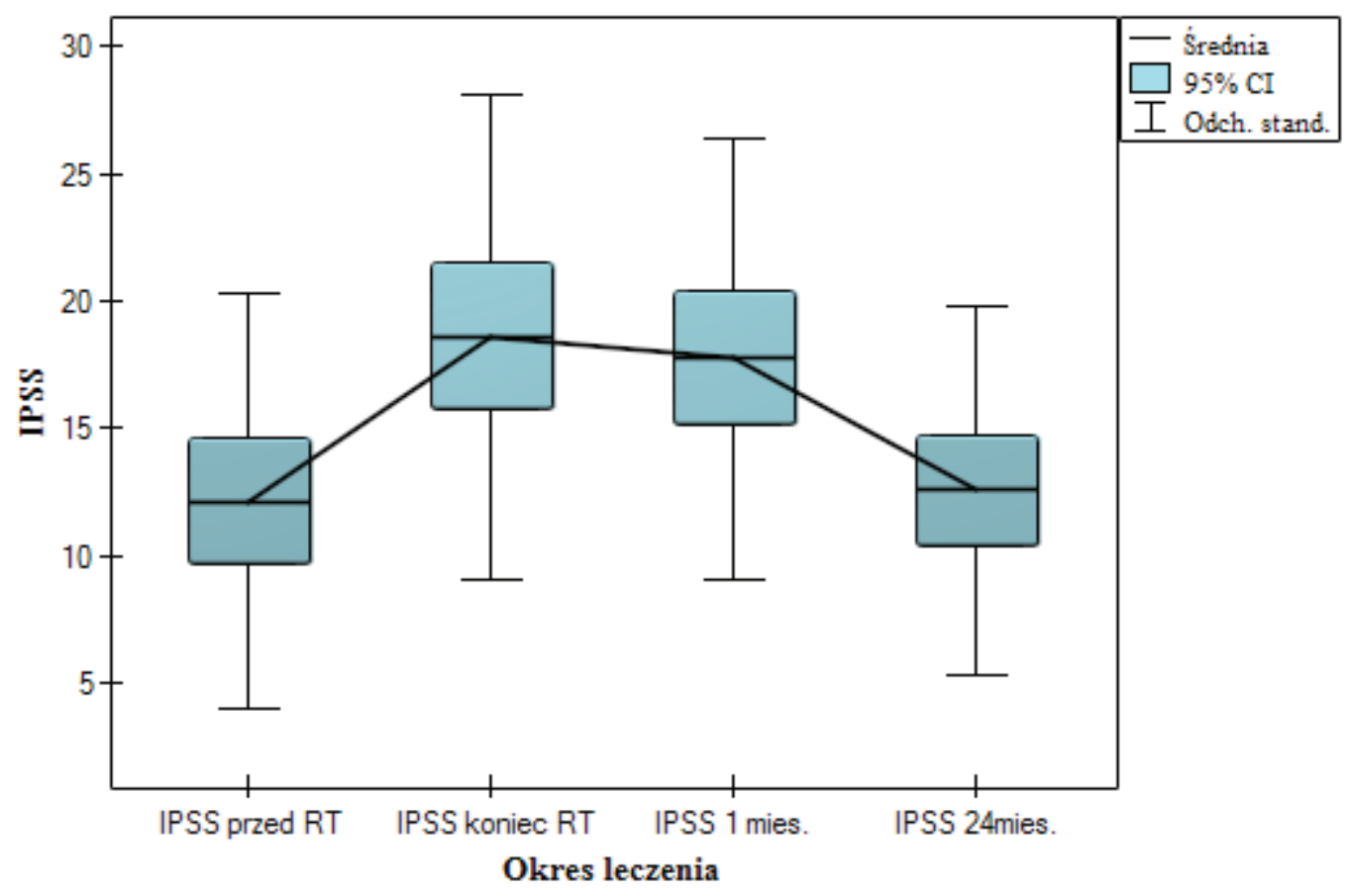

Legenda: 95\% CI- przedział ufności 95\%.

Ryc 1. Zależność średniej wyniku IPSS od okresu leczenia i po 24 miesiącach.

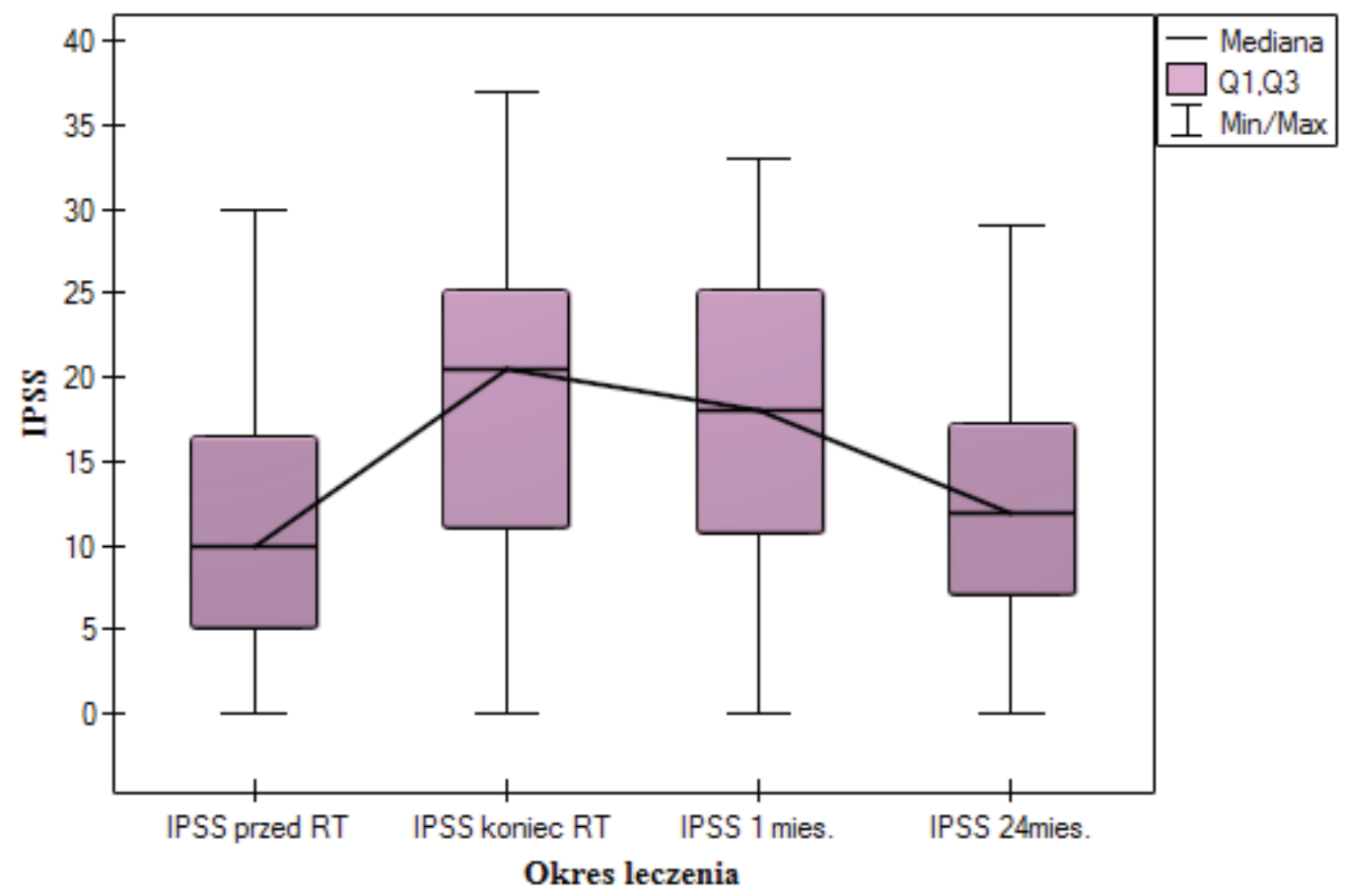

Legenda: Q1, Q3- kwartyl dolny, kwartyl górny.

Ryc 2. Zależność mediany wyniku IPSS od okresu RT i po 24 miesiącach. 
Biorąc pod uwagę wyniki IPSS w całym okresie obserwacji stwierdzono statystycznie istotną różnicę w nasileniu dolegliwości ze strony układu moczowo - płciowego (wartość $\mathrm{p}$ dla testu Friedmana wynosi p= o,000008 dla poziomu istotności 0,05) (tabela nr 3).

Tabela 3. Porównanie wyniku IPSS w różnych okresach leczenia wg testu Friedmana.

\begin{tabular}{|c|c|c|c|c|}
\hline Wartość p & IPSS przed RT & IPSS koniec RT & IPSS 1 miesiąc & IPSS 24 miesiące \\
\hline IPSS przed RT & & 0,000087 & 0,000739 & 0,962398 \\
\hline IPSS koniec RT & 0,000087 & & 1 & 0,020252 \\
\hline IPSS 1 miesiąc & 0,000739 & 1 & 0,089133 \\
\hline IPSS 24 miesiące & 0,962398 & 0,020252 & 0,089133 & \\
\hline
\end{tabular}

Wynik testu Friedmana wskazuje na statystycznie istotną różnicę w wyniku IPSS między nasileniem symptomów występujących przed leczeniem do stanu na końcu radioterapii oraz 1 miesiąc po jej zakończeniu - nastąpił znaczny wzrost wyniku średniej sumy IPSS, co świadczy o nasileniu objawów ze strony prostaty. Wynik zanotowany na początku obserwacji nie różnił się statystycznie od wyniku po 24 miesiącach po leczeniu, co wskazuje na dobrą tolerancję leczenia (tabela 3). Analiza zmiany stopnia nasilenia objawów według kwestionariusza IPSS w trakcie całego okresu obserwacji pacjentów. Tolerancję RT można określić na podstawie występowania oraz stopnia nasilenia objawów będących skutkiem oddziaływania promieniowania jonizującego na dany obszar ciała. Skutkami ubocznymi RT raka stercza może być nietrzymanie moczu, trudności z jego oddawaniem lub ból występujący w trakcje mikcji. Są to jednak objawy, które z czasem ustępują.

W badanej grupie pacjentów mierzony był poziom nasilenia objawów ze strony układu moczowo-płciowego w różnych okresach leczenia. Wyniki te zostały przedstawione na wykresie 1. Można zauważyć, że występuje znaczny wzrost wartości w okresie końca RT oraz 1 miesiąca po RT, a następnie po 24 miesiącach wartości wracają do poziomu sprzed leczenia.

Analizując wyniki stopnia nasilenia objawów według kwestionariusza IPSS w trakcie całego okresu obserwacji pacjentów, można stwierdzić, że leczenie raka stercza za pomocą ultrahipofrakcjonowanej SBRT jest dobrze tolerowaną metodą leczenia i nie powoduje występowania długotrwałych skutków ubocznych.

\section{Dyskusja}

Oceny tolerancji leczenia raka stercza z zastosowaniem ultrahipofrakcjonowanej radioterapii (SBRT) dokonano na podstawie 24 miesięcznej obserwacji pierwszej grupyleczonych chorych wZakładzie Radioterapii I w Wielkopolskim Centrum Onkologii u których realizowano radioterapie na aparacie Cyberknife firmy Acurray. Pacjenci byli poddawani napromienianiu 5- krotnie, co dwa dni, dawką frakcyjną 7,o Gy - 7,25 Gy do dawki całkowitej 35,o Gy - 36,25 Gy. Średnia wieku analizowanych chorych wynosiła 69 lat, średni wynik PSA - 9, a średni wynik sumy Gleason - 6.

Do oceny stopnia tolerancji RT posłużył kwestionariusz IPSS. Pacjenci wypełniali ankiety zawierające wyżej wymienione kwestionariusze przed leczeniem, po ostatniej frakcji oraz miesiąc i 24 miesiące po leczeniu RT. Za pomocą ankiet mierzony był poziom nasilenia objawów związanych z zaburzeniem oddawania moczu.

Wyniki analizy własnej stopnia nasilenia objawów wg. IPSS wskazują na nasilenie symptomów ze strony układu moczowego na koniec RT i 1 miesiąca po jej zakończeniu oraz spadek tych wartości do poziomu zanotowanego przed leczeniem w ciągu 24 miesięcy od zakończenia RT. Stwierdzono statystycznie istotną różnice w wyniku IPSS pod koniec RT i po 24 miesiącach od zakończenia leczenia. Poważny stopień nasilenia objawów przed RT zgłaszało $20 \%$ pacjentów, po podaniu ostatniej frakcji-52\%, a po 2 letnim okresie obserwacji tylko 16\% badanych. Na podstawie powyższych wyników można stwierdzić, że ultrahipofrakcjonowana RT raka stercza powoduje krótkotrwałe skutki uboczne w postaci dolegliwości ze strony układu moczowego 
takie jak - zwiększona częstość oddawania moczu, uczucie parcia na pęcherz, osłabienie strumienia, nykturia czy ból w trakcie mikcji. Objawy te spowodowane są występowaniem typowych dla RT odczynów popromiennych, które nasilają się pod koniec napromieniania i wraz z czasem ustępują. Po 24 miesiącach od zakończonej RT nie zanotowano wzrostu stopnia dolegliwości, co może świadczyć o braku występowania odczynów późnych po SBRT jednakże, aby dokonać jednoznacznej oceny wymagana jest dłuższa obserwacja.

Powyższe wyniki uzyskane $\mathrm{w}$ materiale własnym są zbieżne $\mathrm{z}$ wynikami uzyskanymi w innych renomowanych ośrodkach onkologicznych które wdrożyły takie leczenie raka stercza z udziałem SBRT [10$15]$.

W wyniku dynamicznego rozwoju metod RT możliwe jest podawanie bardzo wysokich dawek promieniowania powodujących zniszczenie guza nowotworowego, bez wywoływania groźnych dla zdrowia skutków ubocznych. Ultrahipofrakcjonowana RT raka stercza polegająca na podaniu dawki 7,o Gy - 7,25 Gy w pięciu frakcjach do dawki całkowitej 35,o Gy - 36,25 Gy aktualnie jest metodą z wyboru, jednak dzięki znacznemu skróceniu czasu terapii, jej wysokiej skuteczności oraz niskiej toksyczności, z powodzeniem przewyższa dotychczasowe techniki napromieniania i może być brana pod uwagę jako standard w leczeniu raka stercza w przyszłości.

\section{Wnioski}

Na podstawie uzyskanych wyników w tym badaniu, można dokonać potwierdzenia tezy, że hipofrakcjonowana RT jest dobrze tolerowaną przez pacjentów metodą leczenia raka stercza. Otrzymane wyniki ukazują typowe dla RT miednicy mniejszej, występowanie wczesnych odczynów popromiennych układu moczowego, o największym nasileniu pod koniec napromieniania i po miesiącu od jego zakończenia. Mimo występowania dolegliwości związanych z występowaniem odczynów popromiennych, terapia nie wpływa istotnie na obniżenie jakości życia, stopnia funkcjonowania oraz aktywności seksualnej pacjentów, co w połączeniu z krótkim okresem leczenia sprawia, że hipofrakcjonowana RT raka stercza cechuje się dobrą tolerancją przez pacjentów [11-14]. W trakcie badania nie odnotowano przypadków wysokiej toksyczności leczenia, jednak wymagana jest dłuższa obserwacja pacjentów w celu określenia długoterminowych skutków terapii, w tym występowania późnych odczynów popromiennych. Wyniki badania potwierdzają dobrą tolerancję oraz niską toksyczność stereotaktycznej radioterapii prostaty dawką 35-36,25 Gy w pięciu frakcjach u pacjentów z rakiem stercza, co pokrywa się z dotychczasowymi wynikami badań nad tą techniką RT [10-15].

Wyniki badania sugerują, że konwencjonalne metody RT raka stercza mogłoby być w przyszłości zastąpione przez SBRT, lecz aby stało się to standardem w leczeniu raka stercza niezbędne są randomizowane badania porównujące hipofrakcjonowaną RT z innymi metodami napromieniania w celu określenia optymalnej dawki i skuteczności leczenia

\section{Piśmiennictwo / References}

[1] Krajowy Rejestr Nowotworów- Gruczoł krokowy. http://onkologia.org.pl/rak-gruczolu-krokowego/.

[2] Global Cancer Observatory, Globocan 2018; https://gco.iarc.fr/today/home.

[3] Ricco A, Manahan G, Lanciano R. The Comparison of Stereotactic Body Radiation Therapy and IntensityModulated Radiation Therapy for Prostate Cancer by NCCN Risk Groups. Frontiers in Oncology 2016; 6:184.

[4] Głowacki G, Bodusz D, Majewski W. Frakcjonowana radioterapia stereotaktyczna CyberKnifeTM chorych na raka gruczołu krokowego. Journal of Oncology 2012;62(4): 274-282.

[5] King C. Lehmann J. Adler J. Hai J. CyberKnife Radiotherapy for Localized Prostate Cancer: Rationale and Technical Feasibility. Technol Ca Res Treat 2003; 2: 25-29.

[6] Michalewska J. Odczyny popromienne w radioterapii oraz popromienne zapalenie skóry. Zeszyty Naukowe WCO, Letters in Oncology Science 2017;14(4):104-109.

[7] Scott C, Morgan MD, MSc, FRCPC, Karen Hoffman MD, MHSc, MPH, D. Andrew Loblaw MD, MSc, FRCPC, FASCO. Hypofractionated Radiation Therapy for Localized Prostate Cancer: Executive Summary of an ASTRO, ASCO, and AUA Evidence-Based Guideline. Pract Radiat Oncol 2018: 8;354-360. 
[8] Katz A. Stereotactic Body Radiotherapy for Low-Risk Prostate Cancer: A Ten-Year Analysis. Cureus 2017;9(9): e1668.

[9] Cihan Y. The role and importance of SBRT in prostate cancer. Int Braz J Urol 2018;44:1272-1274.

[10] Madsen BL, Hsi RA, Pham HT, Fowler JF, Esagui L, Corman J. Stereotactic hypofractionated accurate radiotherapy of the prostate (sharp). $33.5 \mathrm{~Gy}$ in five fractions for localized disease: first clinical trial results. Int J Radiat Oncol Biol Phys 2007;67(4):1099-105.

[11] Friedland JL, Freeman DE, Masterson-McGary ME, Spellberg DM. Stereotactic body radiotherapy: an emerging treatment approach for localized prostate cancer. Technol Cancer Res Treat 2009;8(5):38792.

[12] Katz AJ, Santoro M, Ashley R, Diblasio F,Witten M. Stereotactic body radiotherapy for organ-confined prostate cancer. BMC Urol 2010;10:1.

[13] King C. Stereotactic body radiotherapy for prostate cancer: current results of a phase II trial. Front Radiat Ther Oncol 2011;43:428-37.

[14] King CR, Brooks JD, Gill, et al. Stereotactic body radiotherapy for localized prostate cancer: interim results of a prospective phase II clinical trial. Int J Radiat Oncol Biol Phys 2009;73:1043-8.

[15] Lartigau E. Stereotactic body radiotherapy. BMJ 2011;343:24. 